\title{
5-Aminolevulinic acid-induced severe hypotension during transurethral resection of a bladder tumor: a case report
}

\author{
Tomoaki Yatabe ${ }^{1 *} \mathbb{D}$, Shigematsu-Locatelli Marie ${ }^{1}$, Hideo Fukuhara ${ }^{2}$, Takeshi Karashima ${ }^{2}$, Keiji Inoue ${ }^{2}$ and \\ Masataka Yokoyama ${ }^{1}$
}

\begin{abstract}
Background: Although 5-aminolevulinic acid (5-ALA) is used for the photodynamic diagnosis of bladder tumors, hypotension is the most commonly observed adverse effect. We present a case of 5-ALA-induced severe hypotension during transurethral resection of a bladder tumor.

Case presentation: A 68-year-old man underwent transurethral resection of a bladder tumor using 5-ALA under general anesthesia. Three hours before anesthesia induction, ALA $20 \mathrm{mg} / \mathrm{kg}$ was administered orally. After anesthesia induction, his blood pressure decreased to $47 / 32 \mathrm{mmHg}$. Although we used phenylephrine and ephedrine, hypotension persisted at 50/33 mmHg. Bolus administration of noradrenaline slightly increased his blood pressure to $65 / 39 \mathrm{mmHg}$. Following this, bolus administration of adrenaline elevated his blood pressure. We decided to perform surgery under continuous administration of adrenaline.

Conclusions: Our case report suggests that anesthesiologists should consider 5-ALA-induced hypotension as a differential diagnosis for hypotension occurring after anesthesia induction. Moreover, ephedrine and phenylephrine might be less effective in treating this condition.
\end{abstract}

Keywords: 5-Aminolevulinic acid, Bladder tumor, Hypotension

\section{Background}

5-Aminolevulinic acid (5-ALA) is a natural amino acid and a precursor of protoporphyrin IX (Pp IX), the final intermediate in the heme biosynthetic pathway [1]. Exogenous administration of 5-ALA leads to the accumulation of Pp IX in cancer cells, as cancerous cells are deficient in an enzyme that converts Pp IX to heme [2]. Since Pp IX is a photosensitizer and emits a red fluorescence upon excitation with visible blue light, 5-ALA is used for the photodynamic diagnosis of malignant cells, including bladder tumors [3-5]. A previous systematic review reported that hypotension was the most common adverse effect of 5-ALA use [6]. We present here the case of 5-ALA-induced severe hypotension during transurethral resection of a bladder tumor.

\footnotetext{
* Correspondence: yatabe@kochi-u.ac.jp

${ }^{1}$ Department of Anesthesiology and Intensive Care Medicine, Kochi Medical

School, Kohasu Oko-cho Nankoku, Kochi 783-8505, Japan

Full list of author information is available at the end of the article
}

\section{Case presentation}

A 68 -year-old man $(165 \mathrm{~cm}, 74 \mathrm{~kg})$ was scheduled for transurethral resection of a bladder tumor using 5-ALA. He had been receiving amlodipine $5 \mathrm{mg}$ and azilsartan $20 \mathrm{mg}$ every morning orally for hypertension. His blood pressure was maintained around 130/70 $\mathrm{mmHg}$. Since he had been diagnosed with pyogenic spondylodiscitis in the fourth/fifth lumber disk region in his forties, general anesthesia was preferred. During the pre-operative examination, chest $\mathrm{X}$-ray, electrocardiogram, and laboratory test findings were normal.

The patient took only amlodipine besylate on the morning of the surgery. Three hours before anesthesia induction, 5-ALA $20 \mathrm{mg} / \mathrm{kg}$ (Alaglio, Chugai Pharmaceutical, Tokyo, Japan) was administrated orally. Just before anesthesia induction, the patient's blood pressure was $98 / 61 \mathrm{mmHg}$ and his heart rate 82 beats/min. Anesthesia was induced with propofol $100 \mathrm{mg}$, rocuronium $50 \mathrm{mg}$, fentanyl $100 \mu \mathrm{g}$, and remifentanil $0.4 \mu \mathrm{g} / \mathrm{kg} / \mathrm{min}$. After $5 \mathrm{~min}$, just before tracheal 
intubation, his blood pressure decreased to $47 / 32 \mathrm{mmHg}$. There were no observed changes in his electrocardiogram, such as ST-T changes or arrhythmia. Although we used phenylephrine at a total dose of $0.2 \mathrm{mg}$ and ephedrine at a total dose of $10 \mathrm{mg}$ over $10 \mathrm{~min}$, hypotension persisted at $50 / 33 \mathrm{mmHg}$. Wheezing and erythema were not observed. Administration of $100 \mathrm{~mL}$ hydroxyethyl starch bolus for a few minutes was unsuccessful in increasing blood pressure. Transthoracic cardiac ultrasonography revealed normal systolic function, no asynergy, and normal size of the inferior vena cava. Bolus administration of noradrenaline at a total dose of $30 \mu \mathrm{g}$ over $6 \mathrm{~min}$ slightly increased blood pressure to $65 / 39 \mathrm{mmHg}$. Arterial blood gas analysis revealed the following: $\mathrm{pH}, 7.350 ; \mathrm{HCO}_{3}{ }^{-}$concentration, $23.2 \mathrm{mmol} / \mathrm{L}$; base excess, $2.3 \mathrm{mmol} / \mathrm{L}$; and lactate concentration, 1.7 $\mathrm{mmol} / \mathrm{L}$. Following this, bolus administration of adrenaline at a total dose of $30 \mu \mathrm{g}$ over $9 \mathrm{~min}$ elevated the blood pressure from $53 / 26$ to $127 / 49 \mathrm{mmHg}$. We decided to perform surgery under continuous administration of adrenaline. Anesthesia was maintained with sevoflurane and remifentanil. The patient's blood pressure and heart rate ranged from $72 / 31$ to $94 / 40 \mathrm{mmHg}$ and from 70 to 85 beats/min, respectively, under the administration of adrenaline at $0.01-0.07 \mu \mathrm{g} / \mathrm{kg} / \mathrm{min}$. On completion of the surgery, he was transferred to the intensive care unit under intubation. Twelve minutes after admission to the intensive care unit, he was extubated as his blood pressure had stabilized at $142 / 56 \mathrm{mmHg}$ under the administration of adrenaline at $0.03 \mu \mathrm{g} / \mathrm{kg} / \mathrm{min}$. Ten minutes after extubation, adrenaline infusion was discontinued. Although his lactate concentration was $5.3 \mathrm{mmol} / \mathrm{L}$ at this time, it decreased to $2.7 \mathrm{mmol} /$ $\mathrm{L}$ after $3 \mathrm{~h}$. His blood pressure and heart rate were stable during his intensive care unit stay. The patient was then transferred to the general ward on day 1 postoperatively. He was discharged without any complications 6 days postoperatively. Three months later, dermatologists performed a skin-prick test on him for propofol, rocuronium, and 5ALA, the results of which were negative. Five months later, he received TUR-Bt under general anesthesia without 5ALA for recurrence of tumor. Although we used propofol and rocuronium, severe hypotension did not occur.

\section{Discussion}

A previous systematic review reported that hypotension was the most common adverse effect of 5-ALA, since hypotension comprised $60 \%$ of these events [6]. A small observational study, which enrolled 20 patients who underwent radical prostatectomy reported that the noradrenalin dose to maintain mean blood pressure within $70-90 \mathrm{mmHg}$ in the 5-ALA group was significantly higher than that in the control group $(0.08 \pm 0.04 \mu \mathrm{g} / \mathrm{kg} / \mathrm{min}$ vs. $0.03 \pm 0.02 \mu \mathrm{g} /$ $\mathrm{kg} / \mathrm{min} ; p<0.01$ ) [7]. Another observational study, which enrolled 38 patients who underwent photodynamic diagnostic ureterorenoscopy using 5-ALA, reported that 20 patients developed hypotension after ingestion of 5-ALA [8]. This study also reported that three patients developed symptomatic hypotension preoperatively. Fluid resuscitation with $250 \mathrm{~mL}$ colloid and $500 \mathrm{~mL}$ saline was successful in increasing blood pressure [8]. Fluid resuscitation might be useful, as the potential mechanism of 5-ALA-induced hypotension might be attributed to the vasodilatory effect induced by Pp IX [7]. A previous retrospective study of 30 patients who underwent photodynamic diagnostic ureterorenoscopy with 5-ALA reported that 13\% of patients developed hypotension, and all patients had taken antihypertensive drugs on the day of surgery [9]. The authors suggested that antihypertensive drugs should be discontinued on the day of surgery. Another study evaluated 5-ALA-induced adverse effects in 90 patients and revealed that a history of hypotension and antihypertensive therapy were independent risk factors for 5-ALA-induced hypotension [10]. Our patient had hypertension and was administered two classes of antihypertensive drugs, namely, calciumchannel blockers and angiotensin II receptor antagonists. Furthermore, our patient took a calcium-channel blocker on the morning of the surgery. Although his normal blood pressure was $130 / 70 \mathrm{mmHg}$, it decreased to $98 / 61 \mathrm{mmHg}$ after ingestion of 5-ALA. This suggests that our patient developed 5-ALA-induced hypotension, based on the findings of previous studies.

A recent review reported that it is important to consider anaphylaxis as a differential diagnosis when perioperative hypotension or bronchospasm do not respond to conventional therapy during general anesthesia [11]. We also suspected anaphylaxis caused by propofol or rocuronium, as hypotension did not respond to conventional drugs such as ephedrine and phenylephrine. Hypotension, bronchospasm, angioedema, and dermatological symptoms are common clinical signs of perioperative allergic reactions [11]. In our case, hypotension was the only symptom. Moreover, allergy skin tests for propofol, rocuronium, and 5-ALA were negative. Severe hypotension did not occur in our patient's subsequent TUR-Bt without 5-ALA. Therefore, we eliminated perioperative allergic reactions as a potential cause of hypotension.

We believe that our case raises two important inferences. First, some patients with 5-ALA-induced hypotension might not respond to conventional therapy, akin to anaphylaxis. As mentioned above, fluid resuscitation and noradrenaline were shown to be effective in previous studies. Bolus administration of $100 \mathrm{~mL}$ hydroxyethyl starch and noradrenaline could not recover our patient's blood pressure, despite the lack of systolic dysfunction and asynergy. Adrenaline should probably be considered in such situations. Second, the use of antihypertensive agents on the morning of the surgery should be reconsidered. Previous studies and our case suggest that a history of hypertension and the use of antihypertensive agents are risk factors of 5- 
ALA-induced hypotension. From the perspective of balancing the risks and benefits, further detailed studies are required to identify the risk factors of 5-ALA-induced hypotension.

In conclusion, our case report suggests that anesthesiologists should consider 5-ALA-induced hypotension as a differential diagnosis for hypotension occurring after anesthesia induction. Moreover, ephedrine and phenylephrine might be less effective in treating this condition.

\section{Abbreviations}

5-ALA: 5-Aminolevulinic acid; Pp IX: Protoporphyrin IX; TUR-Bt: Transurethral resection of a bladder tumor

\section{Acknowledgements}

Not applicable.

\section{Authors' contributions}

TY helped care for the patient and wrote the manuscript. SM and HF helped care for the patient and edited the manuscript. TK helped care for the patient and reviewed the manuscript. KI and MY helped edit the manuscript. All authors read and approved the final manuscript.

\section{Funding}

None.

Availability of data and materials

Not applicable.

Ethics approval and consent to participate

In our hospital, the publication of case reports is exempt from Ethics

Committee approval.

\section{Consent for publication}

Written informed consent was obtained from the patient for publication of this case report.

\section{Competing interests}

The authors declare that they have no competing interests.

\section{Author details}

'Department of Anesthesiology and Intensive Care Medicine, Kochi Medical School, Kohasu Oko-cho Nankoku, Kochi 783-8505, Japan. ²Department of Urology, Kochi Medical School, Kochi, Japan.

Received: 8 August 2019 Accepted: 30 August 2019

Published online: 04 September 2019

\section{References}

1. Namikawa T, Fujisawa K, Munekage E, Iwabu J, Uemura S, Tsujii S, et al. Clinical application of photodynamic medicine technology using lightemitting fluorescence imaging based on a specialized luminous source. Med Mol Morphol. 2018:51:187-93.

2. Sachar M, Anderson KE, Ma X. Protoporphyrin IX: the good, the bad, and the ugly. J Pharmacol Exp Ther. 2016:356:267-75.

3. Chou R, Selph S, Buckley DI, Fu R, Griffin JC, Grusing S, et al. Comparative effectiveness of fluorescent versus white light cystoscopy for initial diagnosis or surveillance of bladder cancer on clinical outcomes: systematic review and meta-analysis. J Urol. 2017;197(3 Pt 1):548-58.

4. Hendricks BK, Sanai N, Stummer W. Fluorescence-guided surgery with aminolevulinic acid for low-grade gliomas. J Neurooncol. 2019;141:13-8.

5. Namikawa T, Yatabe T, Inoue K, Shuin T, Hanazaki K. Clinical applications of 5-aminolevulinic acid-mediated fluorescence for gastric cancer. World J Gastroenterol. 2015:21:8769-75.

6. Osman E, Alnaib Z, Kumar N. Photodynamic diagnosis in upper urinary tract urothelial carcinoma: a systematic review. Arab J Urol. 2017:15:100-9.

7. Eichhorn V, Maerz A, Salomon G, Blanc IF, Reuter DA, Goetz AE. Hemodynamic effects of orally administered delta-ALA during radical prostatectomy. World J Urol. 2013;31:371-6.
8. Bondad J, Aboumarzouk OM, Moseley H, Kata SG. Oral 5-aminolevulinic acid induced photodynamic diagnostic ureterorenoscopy--does the blood pressure require monitoring? Photodiagnosis Photodyn Ther. 2013;10:39-41.

9. Aboumarzouk OM, Mains E, Moseley H, Kata SG. Diagnosis of upper urinary tract tumours: is photodynamic diagnosis assisted ureterorenoscopy required as an addition to modern imaging and ureterorenoscopy? Photodiagnosis Photodyn Ther. 2013;10:127-33.

10. Chung IW, Eljamel S. Risk factors for developing oral 5-aminolevulinic acid-induced side effects in patients undergoing fluorescence guided resection. Photodiagnosis Photodyn Ther. 2013;10:362-7.

11. Garvey LH, Dewachter P, Hepner DL, Mertes PM, Voltolini S, Clarke R, et al. Management of suspected immediate perioperative allergic reactions: an international overview and consensus recommendations. Br J Anaesth. 2019;123:e50-64.

\section{Publisher's Note}

Springer Nature remains neutral with regard to jurisdictional claims in published maps and institutional affiliations.

\section{Submit your manuscript to a SpringerOpen ${ }^{\circ}$ journal and benefit from:}

- Convenient online submission

- Rigorous peer review

- Open access: articles freely available online

- High visibility within the field

- Retaining the copyright to your article

Submit your next manuscript at $\boldsymbol{\nabla}$ springeropen.com 